\title{
Tissue-Specific Metabolic Response of Acanthopanax Senticosus (Rupr. Et. Maxim.) Harms Leaf To UV-B radiation
}

Kexin Wu ( $\sim$ wukexin94@126.com )

Northeast Forestry University School of Forestry https://orcid.org/0000-0002-3430-1384

Jia Liu

Northeast Institute of Geography and Agroecology Chinese Academy of Sciences

Yang Liu

Northeast Forestry University School of Forestry

Wenda Shao

Northeast Forestry University

Zhonghua Tang

Northeast Forestry University

Liqiang Mu

Northeast Forestry University School of Forestry

\section{Research Article}

Keywords: Acanthopanax senticosus (Rupr. et. Maxim.) Harms, UV-B; tissue specificity, targeted metabolomics

Posted Date: April 21st, 2021

DOl: https://doi.org/10.21203/rs.3.rs-419081/v1

License: (c) (i) This work is licensed under a Creative Commons Attribution 4.0 International License. Read Full License 


\section{Abstract}

This study aims to evaluate the effects of medium and high UV-B radiation on leaves of Acanthopanax senticosus (Rupr. et. Maxim.) Harms. Two-year-old potted A. senticosus plant samples were respectively exposed to two levels of artificial, biologically effective UV-B radiation under glasshouse-controlled conditions: $1.972 \mathrm{KJ} / \mathrm{m}^{2}$ and $3.442 \mathrm{KJ} / \mathrm{m}^{2}$. Ordinary sunlight treatment was included as a control group, in which major effects of UV-B were observed. It was discovered that UV-B enhanced the medicinal value (especially eleutheroside $\mathrm{B}$ and $\mathrm{E}$ ) of $A$. senticosus but impaired its growth. The sensitivity of leaves to UV-B radiation varied across different parts of the plant, among which the upper leaves responded most strongly. Furthermore, multiple types of phenolic compounds are synergistically involved in stress resistance in different aspects, including up-regulation of UV-absorbing substances (C6C3C6-type, kaempferol and rutin) and antioxidant enzyme synergists (C6C1-type, salicylic acid) as well as downregulation of antioxidants (C6C3-type, p-coumaric acid). Conclusion of this study may provide a new perspective to improve the exploitation of $A$. senticosus.

\section{Introduction}

Acanthopanax senticosus (Rupr. et. Maxim.) Harms (syn. Eleutherococcus senticosus (Ruprecht \& Maximowicz) Maximowicz) is a deciduous shrub and a member of the Araliaceae family. It grows abundantly in various regions of Russia, China, Korea, Southeast Asia, and north Japan. In China, this species typically grows in forests or shrubs between altitudes from several hundred meters to more than 2000 meters (Wang et al. 2019b). A. senticosus is commonly known as Ciwujia or Siberian ginseng and mainly grows in Shanxi, Hebei, and the north-eastern region in China (Jia et al. 2020). In recent years research interest has been mounting on Chinese herbal medicines, meanwhile various therapeutic effects are increasingly revealed. According to Chinese Pharmacopoeia, $A$. senticosus is a well-known traditional Chinese medicine for applications such as kidney tonifying and tranquilization (Zhang et al. 2020). The main active medicinal components of $A$. senticosus, such as triterperoid, saponins, lignans, flavones and phenolic compounds, are derived from all parts of the plant (Wang et al. 2019a; Chen et al. 2020a). As one of the main active medicinal components of $A$. senticosus, eleutheroside $\mathrm{B}$ has anti-diabetic, antifatigue, sleep-enhancement, neuro-protection and antioxidant effects. It has also been reported that eleutheroside $\mathrm{E}$ has anti-inflammatory, cardioprotective, ischemic, and insulin resistant effects (Shouhei et al. 2018). Moreover, isofraxidin was reported to be anti-cancer and can prevent osteoarthritis, lipid metabolism disorder and Alzheimer's disease (Wang et al. 2020). It is also a functional food known for its anti-fatigue, neuroprotective and immunomodulatory effects. The leaves and fruits of $A$. senticosus are the main edible parts of the plant, specifically, $A$. senticosus leaf is consumed as a functional tea beverage in China. In the United States and Europe, it is known as Ginseng tea and Siberian Ginseng tea. Meanwhile, the widespread use of $A$. senticosus has gradually depleted resources, even causing an ecological crisis (Xu et al. 2020). The consumption of $A$. senticosus root, the most common way, is increasingly replaced by its leaf due to the similar effect. As a renewable resource, $A$. senticosus leaf has the potential to be an alternative resource (Wang et al. 2019a). 
Phenolic compounds belong to one of the most essential groups of plant metabolites. They are secondary metabolites originating from the shikimate, phenylpropanoid and acetate metabolic pathways (Liu et al. 2020a). Phenolic compounds have a variety of functions in plants, including supporting cell wall, protecting plants from herbivores and insects, acting as phytoalexins, signals, and UV-B screening compounds etc. (Santin et al. 2019). In general, phenolic compounds enable plants to adapt to external environment and survive under environmental stresses. Phenols, i.e., phenolic compounds, refer to compounds containing at least one hydroxyl group attached directly to an aromatic nucleus. Phenolic compounds involve a wide variety of structures in nature and can be classified into three types based on the number of transformable hydroxyl groups and their binding positions on the aromatic nucleus: C6-C1type (compounds have a C6-C1 carbon skeleton, such as salicylic acid), C6-C3-type (compounds have a C6-C3 carbon skeleton, such as p-coumaric acid), and C6-C3-C6-type (compounds have a C6-C3-C6 carbon skeleton, flavonoids are representative of this type of compounds) (Liu et al. 2017). In recent years, the biological functions of phenolic compounds have drawn increasing attention. For instance, hypericin and quercetin can significantly inhibit ischemic brain injury and protect hypoxic-ischemic brain cells. Phenols in A. senticosus have also been proved to have similar effect (M. Y. et al. 2020; OrtegaHernandez et al. 2019).

Ultraviolet-B (UV-B) radiation is part of the solar spectrum, wavelengths of which range from $280 \mathrm{~nm}$ to $320 \mathrm{~nm}$. Dating back to the industrial era, the increasing chlorine and bromine compounds emission into the atmosphere led to serious depletion to the stratospheric ozone (Li et al. 2020a; Fina et al. 2017). In the past 50 years, stratospheric ozone reduced by $3-6 \%$, thus UV-B radiation has been increasingly reaching the surface of the earth. Due to the indispensable nature of sunlight to plants, their exposure to UV-B light is inevitable. Increasing irradiation intensity has drawn concerns to the damaging effects of UV-B radiation on plants (Paajanen et al. 2011). UV-B radiation has major effects on plant growth and development. Studies have confirmed that UV-B radiation regulates plant growth, development, photosynthesis, their antioxidant system, endogenous hormones, metabolites, and thus affects the plant production (Yan et al. 2020; Barnes et al. 2016). Previous data showed that UV-B radiation impairs plant growth and photosynthesis, increases epidermal wax, alters stomatal distribution, which is mainly due to the alternation of photosynthetic parameters. High doses of UV-B damage plastid ultrastructure and disrupts photosystem II (PSII) electron transportation (Machado et al. 2017). For example, a few UVinduced morphological changes have been described including diameter and inflorescence height reduction in Arabidopsis rosette (Liao et al. 2020). Continuous exposure to UV-B radiation induces stress responses in plants by modulating feedback loops. Phenols accumulating in plant epidermal layer increase as a screen to protect the sensitive tissues underneath from UV-B damage. Reactive oxygen species (ROS) scavenging is also a key process in plant antioxidant defense. Exposure to UV-B leads to the generation of ROS in the form of superoxide $\left(-\mathrm{O}^{2-}\right)$, hydroxyl radicals $(-\mathrm{OH})$, hydrogen peroxide $\left(\mathrm{H}_{2} \mathrm{O}_{2}\right)$ and singlet oxygen (-0), leading to oxidative stress in plants, which disturbs the balance between oxidants and antioxidants. Plants counteract the negative effects of stress by activating enzymes such as catalase (CAT), superoxide dismutase (SOD), peroxidase (POX), and ascorbate peroxidase (APX), as 
well as non-enzymatic antioxidants, resulting in an efficient ROS scavenging system (Jaiswal et al. 2020; Liu et al. 2020c).

In this study, $A$. senticosus leaves in different plant parts were collected as samples for a model system to perform an integrated analysis on the response of $A$. senticosus leaves to diverse levels of solar UV-B doses. Specifically, the analysis was to determine the influence of UV-B treatment in differing intensities on photosynthetic parameters, oxidative damage and secondary metabolites in leaves at various parts of the plant. To explore in depth the responses and mechanisms of metabolic reprogramming in leaves at different positions under enhanced UV-B radiation, we investigated the influence on specific tissueresponse in terms of physiology and metabolism using untargeted and targeted metabolomic methods in A. senticosus under enhanced UV-B radiation.

\section{Materials And Methods}

\section{Plant material and UV-B treatments}

This experiment was performed in the plant cultivation greenhouse of the Key Laboratory of Forest Plant Ecology of the Ministry of Education, Northeast Forestry University in July $2017\left(126^{\circ} 38^{\prime} \mathrm{E}, 45^{\circ} 43^{\prime} \mathrm{N}\right)$. The experimental materials are two-year-old potted $A$. senticosus plants. To begin with, 30 pots of uniform grown $A$. senticosus plants were selected and randomly divided into 3 groups, with 10 plants in each group. One group was the control check group (CK) and the other two were treatment groups. A UV-B lamp was used as a radiation source, and the radiation intensity was measured by a spectrometer AveSpec 2048-2 (Avantes BV, Netherlands). Based on the control group (natural solar light), UV-B radiation of $1.972 \mathrm{KJ} / \mathrm{m}^{2}$ and $3.442 \mathrm{KJ} / \mathrm{m}^{2}$ was artificially applied in addition as the Medium UV-B stress (MU) group and High UV-B stress (HU) group, respectively. UV treatment was fixed for 2 hours per day, 14 days in total. After treatment, the growth indexes of $A$. senticosus were measured, and the upper, middle and lower leaves of each group were collected for the determination of various factors.

\section{Gas exchange and chlorophyll fluorescence}

The Li-6400 portable photosynthesis system analyzer (LI-COR Inc. USA) was used to determine the leaf gas exchange parameters. Leaves on different parts of plants after UV-B radiation were analyzed under the condition of $6400-02 B$ LED light source, relative air humidity of $50 \%$, air temperature of $25{ }^{\circ} \mathrm{C}$, carbon dioxide concentration of $500 \mu$ mols- 1 , and photon flux density of $1200 \mu \mathrm{molm}-2 \mathrm{~s}-1$. Net photosynthetic rate (Photo), stomatal conductance (Cond), intercellular $\mathrm{CO} 2$ concentration (Ci), and transpiration rate (Trmmol) were measured. In addition, 3 biological replicates were performed for each group.

A portable PAM-2500 chlorophyll fluorometer was employed to determine chlorophyll fluorescence parameters. Tested leaves were subjected to dark treatment for 15 minutes in advance to complete adaptation to darkness. After the pretreatment, the maximum fluorescence yield under light ( $\left.F \mathrm{Fm}^{\prime}\right)$, the minimum fluorescence under light $(\sim$ Fo'), the actual photosynthetic quantum yield $(\mathrm{Y}(\mathbb{\nabla}))$, the quantum yield for regulating energy dissipation ( $(\mathrm{NPQ})$ ), non-regulated energy dissipation quantum yield $(\mathrm{Y}(\mathrm{NO})$ ), 
non-photochemical quenching coefficient (qN), photochemical quenching coefficient (qL) and maximum photosynthetic quantum yield (Fv/Fm) were measured. Three biological replicates were performed for each group, and the mean value was used for analysis.

\section{Determination of malondialdehyde (MDA) and proline}

$0.5 \mathrm{~g}$ leaf sample was weighed and homogenized in $2 \mathrm{ml}$ chilled reagent, which contained $0.25 \%(\mathrm{w} / \mathrm{v})$ TBA (thiobarbituric acid) in $10 \%(\mathrm{w} / \mathrm{v})$ TCA (trichloracetic acid). The supernatant was retained after centrifugation (10,000 rpm, $20 \mathrm{~min}$ ), heated at $95^{\circ} \mathrm{C}$ for $30 \mathrm{~min}$ and then rapidly cooled and centrifuged again (10,000 rpm, $20 \mathrm{~min}$ ). The absorbances at $532 \mathrm{~nm}, 600 \mathrm{~nm}$ and $450 \mathrm{~nm}$ were measured respectively to calculate the MDA content (Ma et al. 2015).

$0.20 \mathrm{~g}$ A. senticosus leaf sample was weighed, added in $3 \%$ sulfosalicylic acid solution, and centrifuged (10 $000 \mathrm{rpm}, 15 \mathrm{~min}$ ). Afterwards, $2 \mathrm{~mL}$ supernatant was collected and then $2 \mathrm{~mL}$ glacial acetic acid and $2 \mathrm{~mL}$ acidic ninhydrin were added; the obtained solution was treated in boiling water bath for $1 \mathrm{~h}$ until turning red, then cooled rapidly in an ice bath to terminate the reaction. The absorbance value of the upper red toluene solution at $520 \mathrm{~nm}$ was measured (Bates et al. 1973).

\section{Determination of antioxidant enzyme}

$0.5 \mathrm{~g}$ precisely weighed plant sample were extracted in $10 \mathrm{~mL} 50 \mathrm{mM}$ phosphate buffer $(7.8 \mathrm{pH})$ containing $1 \mathrm{mM}$ 2-mercaptoethanol, $2 \%$ polyvinylpyrrolidone (PVP) and $1 \mathrm{mM}$ EDTA. The supernatant was retained after centrifugation $\left(4^{\circ} \mathrm{C}, 14000 \mathrm{rpm}\right.$ ) and stored at $-20^{\circ} \mathrm{C}$ for enzymatic antioxidants (CAT, POD, APX, and SOD) activity testing (Kohler et al. 2017; Contreras et al. 2019).

\section{Superoxide dismutase (SOD)}

A reaction mixture was prepared using $600 \mu \mathrm{L}$ of sodium phosphate buffer (50 mM, pH 7.5), $10 \mu \mathrm{L}$ of $10 \mathrm{mM}$ EDTA, $100 \mu \mathrm{L}$ of $130 \mathrm{mM}$ methionine, $10 \mu \mathrm{L}$ of $2 \mathrm{mM}$ riboflavin, $200 \mu \mathrm{L}$ of $3 \mathrm{mM}$ of nitroblue tetrazolium (NBT) in 70\% dimethyl formamide (DMF) and $100 \mu \mathrm{L}$ of protein extract. After incubation in the dark for $15 \mathrm{~min}$, NBT reduction was recorded at $560 \mathrm{~nm}$.

\section{Peroxidase (POD)}

A reaction mixture containing $1 \mathrm{~mL} 50 \mathrm{mM}$ sodium phosphate buffer $(\mathrm{pH} 7.5), 10 \mu \mathrm{L}$ of protein extract, 5 $\mu \mathrm{L}$ of $100 \mathrm{vol}$. hydrogen peroxide and $5 \mu \mathrm{L}$ of guaiacol was prepared. The absorbance at $470 \mathrm{~nm}$, indicating the activity of POD in tetrahydroguaiacol (THG) formation, was recorded after 1 min reaction.

\section{Ascorbate peroxidase (APX)}

A reaction mixture containing $0.1 \mathrm{M}$ phosphate buffer ( $\mathrm{pH} 7.5), 0.5 \mathrm{mM} \mathrm{H} 2 \mathrm{O} 2,5 \mathrm{mM}$ ascorbic acid, 0.1 $\mathrm{mM}$ EDTA and $0.1 \mathrm{~mL}$ enzyme extract were prepared. After $1 \mathrm{~min}$ reaction, the absorbance at $290 \mathrm{~nm}$ was recorded and the activity of APX was calculated. 


\section{Catalase (CAT)}

Reaction mixture containing $0.1 \mathrm{M}$ phosphate buffer $(7.8 \mathrm{pH}), 200 \mathrm{mM} \mathrm{H} 2 \mathrm{O} 2$, and the enzyme extract was prepared. The absorbance at $240 \mathrm{~nm}$, indicating CAT activity in terms of hydrogen peroxide consumption, was recorded after 1 min reaction.

\section{LC-MS analysis}

Approximately $1 \mathrm{~g}$ dry-powdered plant material was extracted with $10 \mathrm{~mL}$ of methanol (80\%) under reflux for $45 \mathrm{~min}$, filtered and the filtrate was collected. The supernatant was retained after centrifugation $\left(4^{\circ} \mathrm{C}\right.$, $14000 \mathrm{rpm}$ ) and the extract was concentrated to dryness by evaporation under vacuum. The extract was then dissolved in $1.0 \mathrm{~mL}$ methanol. All samples were filtered through a $0.22 \mu \mathrm{m}$ diameter micropore and directly fed to LC-MS analysis. In this experiment, the contents of five active ingredients in $A$. senticosus were determined using UPLC-MS system, and the data was analyzed through Analyst 1.4.2 (AB SCIEX, Concord, ON, Canada). UPLC-QTOF-MS was employed to determine 14 phenolic compounds in $A$. senticosus, data of which was collected with MassLynx software v 4.1 (Waters, Milford, MA, USA). Assay conditions were referred to previous studies (Liu et al. 2018b; Wu et al. 2018).

\section{Statistical analysis}

All measurements of the experiment were performed in triplicate, and all parameters were analyzed using one-way ANOVA or two-way ANOVA with Tukey's post-testing respectively via SPSS 17.0 (SPSS, Inc., Chicago, IL USA).

\section{Results}

\section{Effect of UV-B radiation on chlorophyll fluorescence and gas exchange parameters}

When UV-B radiation intensity increased, it caused damage to leaves and inhibited their growth (Figure 1). After 7-day treatment, net photosynthetic rate (photo) of leaves in every position on $A$. senticosus plants significantly decreased as the UV intensity increased (Figure 2). Intercellular $\mathrm{CO}_{2}$ concentration (Ci) and transpiration rate (Trmmol) both showed similar changes. Under severe UV stress, net photosynthetic rate of leaves in all positions decreased significantly to about $50 \%$ of the control group. In the MU-treatment group, Ci shows an increment, while HU treated plants revealed a significant Ci decrease. It can be known from the two-factor variance analysis (Table S1) that the net photosynthetic rate, stomatal conductance, intercellular carbon dioxide concentration, and transpiration rate index on different leaf positions are significantly affected by the individual factor, UV-B radiation, at different intensities $(p<0.01)$; the effect

of $\mathrm{Ci}$ and Trmmol on leaf position $\times$ treatment interaction factors was also extremely significant $(p<0.01)$, and the interaction of leaf position $\times$ treatment had significant impact on stomatal conductance $(p$ $<0.05)$. Nevertheless, the net photosynthetic rate revealed no notable correlation to leaf position $x$ treatment interaction factors. 
It can be observed from Figure 3 that $Y$ (II) gradually decreased after the exposure to UV-B stress. This indicates that UV-B radiation reduced the actual photosynthetic capacity of $A$. senticosus, which occurred at various leaf positions. Meanwhile, the maximum quantum yield (Fv/Fm), non-photochemical quenching (qN), and the quantum yield that regulates energy dissipation in plant photosystem II (Y(NPQ)) exhibited similar trends. Nevertheless, the change in quantum yield of non-regulatory energy dissipation $(\mathrm{Y}(\mathrm{NO}))$ was relatively weak.

\section{Effects of UV-B radiation on osmotic adjustment, membrane damage and antioxidant system}

To understand the effects of UV-B stress on membrane damage and osmoregulation in A. senticosus leaves, the contents of malondialdehyde (MDA) and proline were measured. Figure 4 suggests that the response of the upper leaves to UV-B was more prominent. The contents show a graded increase as the UV radiation intensified, comparing to the middle and lower leaves.

As UV-B radiation intensity increased, the activity of APX, CAT, and POD in each leaf position of $A$. senticosus first enhanced, then declined. CAT and SOD activities of each component decreased in the lower leaves, whereas no significant distinction was observed in APX and POD activities at different leaf positions (Figure 5). All four antioxidant enzymes were significantly affected by treatment factors ( $p$ $<0.01$ ), but the influence of interaction of leaf position $\times$ treatment was not significant. Leaf position has significant effects on CAT and SOD activities (Table S2).

\section{Changes of medicinal ingredients under UV-B radiation}

By optimizing the experimental conditions, the optimal chromatographic and mass spectrometric conditions for the target compounds determination were finally achieved. Standard curves of five compounds were obtained, and the absolute content of active ingredients in each leaf position of $A$. senticosus after UV-B irradiation was calculated (Table S3). In this experiment, saponin B and E (i.e., eleutheroside $B$ and $E$ ) were determined. Saponin concentration in the upper leaves of $A$. senticosus was the highest in response to UV-B radiation, which is positively associated with radiation intensity (Figure 6). Eleutheroside B content in MU- and HU-treated group was respectively 1.5 and 1.9 times than that of the control group; content of eleutheroside $E$ treatment group was respectively 1.9 and 3.5 times than that of the control group. In consequence, the yield of saponins in the leaves significantly increased. Under middle stress, the content of oleanolic acid, isofraxidin and hyperoside in the upper and lower leaves significantly increased; under high stress, the content of isofraxidin and hyperoside in all leaves increased, whereas the content of oleanolic acid decreased. Through the analysis of the principal component $\mathrm{Q}$ value, the comprehensive scores of the active ingredients in each leaf position under high stress significantly improved, and more active ingredients accumulated in the upper and lower leaves after UV-B treatment (Figure 6). All five medicinal active ingredients in A. senticosus were significantly ( $p$ $<0.01$ ) affected by individual factors, either leaf position or treatment, as well as the combination of leaf position and treatment (Table S4).

\section{Effects of UV-B radiation on phenolic compounds}

Page $7 / 23$ 
We investigated the accumulation of phenolics in different tissues under UV-B treatment. Visualization of the phenolics was performed by hierarchical cluster analysis (Figure 7). The accumulation of phenolics revealed a distinct variation in terms of their abundance in different positions of plant and under different levels of stress. Phenolic compounds are generally classified into three types according to their molecular structures, namely C6C3C6-type, C6C3-type and C6C1-type. Based on the tissue-specific accumulation patterns, the 14 phenols detected in this study are categorized into 3 main clusters. Phenolics in cluster 1 exhibit significantly higher abundance in the number of accumulated compounds under MU treatment, which mainly consist of C6C1-type (p-hydroxybenzoic acid, salicylic acid, syringic acid). There are 3 types of compounds accumulating in Cluster 2, namely C6C1-type (vanillic acid), C6C3-type (chlorogenic acid, caffeic acid, p-Coumaric acid, genistein) and C6C3C6-type (quercetin), revealing major accumulation in upper leaves, contents of which were significantly reduced by UV-B treatment. The accumulation of cluster 3 , mainly including flavonoids ( $6 \mathrm{C} 3 \mathrm{C} 6$ ) phenolic compounds such as kaempferol and rutin, is generally higher than that of control group.

\section{Correlation Analysis of target compounds and antioxidant enzymes}

In order to study the comprehensive influence of UV-B radiation on the leaf metabolism of $A$. senticosus and the relationship among antioxidant enzyme activity, major medicinal components and phenolic compounds, correlation analysis was performed on related compounds and enzyme activities, using $\mathrm{R}$ language for heat map drawing (Figure 8). Correlation analysis shows that L-phenylalanine, a precursor of phenolic compounds, has significantly negative correlations between salicylic acid and SOD $(p<0.05)$. C6C1-type compounds (syringic acid and salicylic acid) present significant positive correlations $(p<0.05)$ with APX, CAT and POD. Correlation between kaempferol (C6C3C6) and rutin, which are the same type of compound, was significantly positive $(p<0.05)$. Moreover, correlations between caffeic acid and $p$ hydroxycinnamic acid $(p<0.01), p$-coumaric acid $(p<0.01)$ (C6c3-type) and chlorogenic acid $(p<0.05)$ are significantly positive, respectively, whereas correlations between caffeic acid and APX $(p<0.05), P O D$ $(p<0.05)$ are significantly negative, respectively. Among the medicinal active ingredients of $A$. senticosus, isofraxidin and C6C3-type compounds (genistein, chlorogenic acid, and p-coumaric acid) suggest significant negative correlations $(p<0.05)$, while hyperoside revealed significant negative correlation $(\mathrm{p}<0.05)$ between $\mathrm{p}$-hydroxycinnamic acid as well as $\mathrm{p}$-Coumaric acid (C6C3), respectively. In addition, the contents in A. senticosus exhibits no notable correlation with the accumulation of phenolic compounds and antioxidant enzyme activity.

\section{Discussion}

The interference of environmental factors in plants can directly reflect in their phenotypic changes, since plants adjust their morphological features to adapt to external conditions (Takshak and Agrawal 2019). On exposure to intense UV-B radiation, multiple physiological activities of the plant will be affected, such as stomatal conductance reduction, chemical composition changes of leaves, and damage to the photosynthetic system to a certain extent (Dillon et al. 2018). Specifically, photosynthetic rate is closely related to stomatal conductance and intercellular $\mathrm{CO}_{2}$ concentration. Studies have discovered that 
environmental stresses influence the photosynthetic rate through the interaction of these two factors. The results of this study demonstrate that after increasing the intensity of UV-B radiation, $\mathrm{Ci}$ in A. senticosus first increases, then decreases (Fig. 2). According to Zeiger and Field (1982), two reasons are responsible for the decline in photosynthetic rate, i.e., stomatal and non-stomatal limitation. Consequently, the reduction of photosynthetic rate of $A$. senticosus under UV-B radiation may be affected by non-stomatal limiting factors (Zeiger and Field 1982). On measuring and analyzing chlorophyll fluorescence, a widelyapplied probe of the interaction of external environment and photosynthesis, the response mechanism of plant photosynthesis system to environmental changes can be detected (Li et al. 2020b). This experiment demonstrated that increasing UV-B radiation significantly reduced the chlorophyll fluorescence parameter indicators such as $\mathrm{Y}(\mathbb{\nabla}), \mathrm{Fv} / \mathrm{Fm}, \mathrm{qN}, \mathrm{Y}(\mathrm{NPQ})$ in leaves at all parts of $A$. senticosus plant (Fig. 3). As a mutual support, UV-B radiation has been proved to reduce the chlorophyll fluorescence parameters in rice in previous studies (Razack and Lee 2013). The possible reason for the decrease is the UV-B effects on

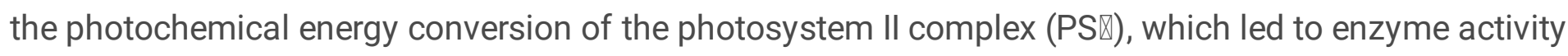
impairment and electron transporter reduction, and subsequently reduced the conversion efficiency of light energy.

When receiving UV-B radiation, plant will active its defense system and enhance the activity of related enzymes in the antioxidant system to prevent damage caused by reactive oxygen (Jaiswal et al. 2020). Studies of Rao et al. (1996) and Zhang et al. (2020) proved that UV-B radiation significantly increases POD activity and reduces CAT activity in Arabidopsis as well as wheat, indicating major differences of plants in response to UV-B radiation. Results of this study suggest that, the antioxidant enzymes in $A$. senticosus increase under moderate stress to actively prevent the damage caused by UV-B radiation, whereas under severe stress, the amount of UV-B radiation is beyond the self-defense capacity of $A$. senticosus antioxidant enzyme system, resulting in enzyme activity reduction (Yang et al. 2007).

Plant leaves do not fully absorb UV-B radiation, as the wax layer on leaves reflects a small portion away. The remaining large amount of UV-B reaches the epidermal cells through the wax layer (Berli et al. 2011). The majority of many UV-absorbing substances is inside the epidermal cells, effectively protecting mesophyll cells, thereby reducing UV-B damage (Kusano et al. 2011). This reaction is considered to be a long-term, complete self-protection system that gradually evolves during a plant lifecycle. Ultravioletabsorbing substances can effectively absorb UV-B, reducing its damage to protein macromolecules and nucleic acids (Contreras et al. 2019). The effects of UV-B on the UV-absorbing substances in different plants vary significantly (Chen et al. 2020b; Cvikrova et al. 2016). Therefore, research on the changes of various UV-absorbing compounds helps further understand the plant response to UV-B as well as the impact of UV-B on plants (Liu et al. 2020b). Nevertheless, UV-absorbing substances cannot provide full protection for plants against UV-B, as a result the influence of UV-B on plant secondary metabolites and the whole system still requires further detailed research (Gao et al. 2019; Gil et al. 2012). Regulating secondary metabolite accumulation pattern is the most direct way for plants to adapt to environmental changes. In this study of UV-B effects on medicinal components in A. senticosus leaves, saponin compounds revealed a similar changing pattern, with high tissue specificity after treatment. Similar results were observed in the study of Curcuma caesia Roxb. (Jaiswal et al. 2020). Other compounds are 
either produced through different secondary metabolic synthesis pathways, or key synthetic genes and enzymes exhibit different activity modes, leading to diverse changing patterns under UV-B stress.

When plants receive potentially destructive UV-B radiation, they synthesize and accumulate UV-absorbing compounds as a protective mechanism, most of which are phenolic compounds (Yan et al. 2020). Therefore, the study of phenolic compounds is essential to understanding plant response to UV-B radiation (Vidovic et al. 2015). In this study, 14 phenolic compounds in A. senticosus leaves were measured. Phenolic compounds with different structures exhibit notable tissue specificity (Fig. 7). However, the response of plants to UV-B radiation depends on the intensity of the radiation, exposure time and species. similarly, the responses of phenolic compounds with different structures to UV-B are also different (Pieriste et al. 2020; Inostroza-Blancheteau et al. 2014). Some studies illustrated that Lactuca sativa L. shoots are more sensitive to UV-B radiation than adult leaves (Behn et al. 2011). Results from a study on Citrus aurantifolia demonstrated that leaves exhibited different sensibility to solar UV-B during different development stages, in terms of UV-B absorbing compounds production (Ibanez et al. 2008). The correlation between leaf age and UV-B radiation remains controversial today. In this study, Lphenylalanine, a precursor of phenolic compounds, revealed significant tissue specificity in the distribution in $A$. senticosus leaves, with major accumulation in the lower leaves, which declines progressively in upper positions of the plant. This distinction remains after UV-B treatment. It indicates that although the metabolic flux of phenolic compound in different leaf positions in A. senticosus shows a stable trend after exposure to UV-B radiation, understanding the changes of different types of phenolic compounds requires further investigation.

Application of UV-B radiation has been proposed as a safe, cheap, non-molecular method to enhance the production of phenolic compounds in Ocimum basilicum L. and other horticultural crops during postharvest life (Ghasemzadeh et al. 2016). To resist UV-B damage, flavonoids are one of the key substances in plants(Liu et al. 2020c; Henry-Kirk et al. 2018). They can absorb or filter ultraviolet photons in some leaves, reduce the UV-B dose that enters the cells, thus reduce the damage to cells (Ghasemzadeh et al. 2016; Clayton et al. 2018). The biosynthetic pathway of C6C3C6-type compounds results in the production of flavonoids (flavonols) and isoflavones (Liu et al. 2018a; Liu et al. 2018b). In our results, the accumulation of kaempferol and rutin increased significantly after UV-B treatment, especially under moderate radiation, suggesting that they are the main ultraviolet absorbing substances. Salicylic acid (C6C1-type), a compound that reduces the risk of long-term heart disease in diabetic patients, increases significantly in A. senticosus plants when exposed to moderate UV-B radiation (Farthing et al. 2007; Nulton-Persson et al. 2004; Eisen et al. 2009; Dervisevik et al. 2014). Therefore, it can be inferred that an appropriate amount of UV-B radiation application to the plant may improve the medicinal effect of $A$. senticosus extract, with relation to heart disease and diabetes. Moreover, salicylic acid was significantly positively correlated with various antioxidant enzymes $(p<0.05)$, whereby the same result revealed on the compound in the same category, syringic acid. This suggests that both salicylic acid and syringic acid are likely to be involved in plant UV resistance. Moreover, p-coumaric acid (C6C3-type) is known as an effective antioxidant that is responsible for ABTS (2,2'-azinobis-(3ethylbenzthiazoline-6-sulphonic acid)) free radical scavenging (Ru et al. 2019; Boz 2015). P-coumaric 
acid accumulation in this study was significantly lower, which is possibly due to this mechanism. The responses to UV-B that differ to phenolic compounds with different structures can be considered as one of the strategies to modulate plant defense against UV-B radiation.

\section{Conclusion}

In conclusion, this study is a comprehensive investigation on the response of leaves at different positions of $A$. senticosus plant on exposure to various levels of UV-B radiation. The upper leaves were most sensitive to UV-B radiation, whereby the radiation affected their growth, including reduced leaf area, photosynthetic system capacity decrease, and membrane damage, but actually improved its overall medicinal production. Nevertheless, the accumulation of eleutheroside B and E increased significantly. After UV treatment, phenolic compounds were involved in damage resistance in multiple aspects and showed a cooperative response to UV-B radiation with the antioxidant system. The accumulation of kaempferol and rutin, the main UV-absorbing substances in A. senticosus, increased rapidly. The C6C1type compounds (syringic acid and salicylic acid) were likely to function synergistically with the antioxidant enzymes to resist damage. However, when the stress was intensified, the protection capacity of the antioxidant enzyme system was exceeded.

In this study, it is demonstrated that higher intensity of radiation can enhance the content of medicinal active ingredients of $A$. senticosus and different phenolic compounds responses to UV-B are discovered. We suggest further studies to focus on the targeted modulation of phenolic compounds on enhancing UV-B tolerance in $A$. senticosus, which will provide new insights to improve the quality of $A$. senticosus.

\section{Declarations}

Funding This work was supported by the Fundamental Research Funds for the Central Universities (2572020AW11), Forestry science and Technology Extension Project ([2019]12), Biosafety and Genetic Resource Management Project (KJZXZH202001).

Availability of data and material All data is available on request to corresponding author.

Conflict of interest The authors declare that they have no conflict of interest.

Code availability Not applicable.

Authors' contributions All the authors listed have approved the manuscript.

\section{References}

1. Jia A, Zhang Y, GaoH, Zhang Z, Zhang Y, Wang Z, Zhang J, Deng B, Qiu Z, Fu C (2020) A review of Acanthopanax senticosus (Rupr and Maxim.) harms: From ethnopharmacological use to modern application - ScienceDirect. Journal of Ethnopharmacology 268 
2. Barnes PW, Tobler MA, Keefover-Ring K, Flint SD, Barkley AE, Ryel RJ, Lindroth RL (2016) Rapid modulation of ultraviolet shielding in plants is influenced by solar ultraviolet radiation and linked to alterations in flavonoids. Plant Cell Environment 39(1):222-230. doi:10.1111/pce.12609

3. Bates LS, Waldren RP, Teare ID (1973) Rapid Determination of Free Proline for Water-Stress Studies. Plant Soil 39(1):205-207

4. Behn H, Schurr U, Ulbrich A, Noga G (2011) Development-dependent UV-B Responses in Red Oak Leaf Lettuce (Lactuca sativa L.): Physiological Mechanisms and Significance for Hardening. Eur J Hortic Sci 76(2):33-40

5. Berli FJ, Fanzone M, Piccoli P, Bottini R (2011) Solar UV-B and ABA Are Involved in Phenol Metabolism of Vitis vinifera L. Increasing Biosynthesis of Berry Skin Polyphenols. J Agr Food Chem 59(9):4874-4884. doi:10.1021/jf200040z

6. Boz H (2015) p-Coumaric acid in cereals: presence, antioxidant and antimicrobial effects. Int J Food Sci Tech 50(11):2323-2328. doi:10.1111/ijfs.12898

7. Chen L, Xin X, Feng H, Li S, Cao Q, Wang X, Vriesekoop F (2020a) Isolation and Identification of Anthocyanin Component in the Fruits of Acanthopanax Sessiliflorus (Rupr. et. Maxim.) Seem. by Means of High Speed Counter Current Chromatography and Evaluation of Its Antioxidant Activity. Molecules 25:(8)

8. Chen Y, Shen Q, Lv P, Sun CB (2020b) Comparative metabolomic analyses of Dendrobium officinale Kimura et Migo responding to UV-B radiation reveal variations in the metabolisms associated with its bioactive ngredien. Peerj 8. doi:ARTN e910710.7717/peerj.9107

9. Clayton WA, Albert NW, Thrimawithana AH, McGhie TK, Deroles SC, Schwinn KE, Warren BA, McLachlan ARG, Bowman JL, Jordan BR, Davies KM (2018) UVR8-mediated induction of flavonoid biosynthesis for UVB tolerance is conserved between the liverwort Marchantia polymorpha and flowering plants. Plant J 96(3):503-517. doi:10.1111/tpj.14044

10. Contreras RA, Pizarro M, Kohler H, Zamora P, Zuniga GE (2019) UV-B shock induces photoprotective flavonoids but not antioxidant activity in Antarctic Colobanthus quitensis (Kunth) Bartl. Environ Exp Bot 159:179-190. doi:10.1016/j.envexpbot.2018.12.022

11. Cvikrova M, Vondrakova Z, Eliasova K, Pesek B, Travnickova A, Vagner M (2016) The impact of UV-B irradiation applied at different phases of somatic embryo development in Norway spruce on polyamine metabolism. Trees-Struct Funct 30(1):113-124. doi:10.1007/s00468-015-1280-6

12. Dervisevik M, Dinevska-Kovkarovska S, Dimitrovska M, Cipanovska N, Miova B (2014) High dose of aspirin moderates diabetes-induced changes of heart glycogen/glucose metabolism in rats. $J$ Physiol Sci 64(6):411-420. doi:10.1007/s12576-014-0335-6

13. Dillon FM, Chludil HD, Reichelt M, Mithofer A, Zavala JA (2018) Field-grown soybean induces jasmonates and defensive compounds in response to thrips feeding and solar UV-B radiation. Environ Exp Bot 156:1-7. doi:10.1016/j.envexpbot.2018.08.022

14. Eisen DP, Corey GR, McBryde ES, Fowler VG, Miro JM, Cabell CH, Street AC, Paiva MG, Ionac A, Tan RS, Tribouilloy C, Pachirat O, Jones SB, Chipigina N, Naber C, Pan A, Ravasio V, Gattringer R, Chu VH, 
Bayer AS, Investigators I (2009) Reduced valve replacement surgery and complication rate in Staphylococcus aureus endocarditis patients receiving acetyl-salicylic acid. J Infection 58(5):332338. doi:10.1016/j.jinf.2009.03.006

15. Farthing D, Gehr L, Karnes HT, Sica D, Gehr T, Larus T, Farthing C, Xi L (2007) Effects of salicylic acid on post-ischaemic ventricular function and purine efflux in isolated mouse hearts. Biomarkers 12(6):623-634. doi:10.1080/13547500701605786

16. Fina J, Casadevall R, AbdElgawad H, Prinsen E, Markakis MN, Beemster GTS, Casati P (2017) UV-B Inhibits Leaf Growth through Changes in Growth Regulating Factors and Gibberellin Levels. Plant Physiol 174(2):1110-1126. doi:10.1104/pp.17.00365

17. Gao LM, Liu Y, Wang XF, Li YF, Han R (2019) Lower levels of UV-B light trigger the adaptive responses by inducing plant antioxidant metabolism and flavonoid biosynthesis in Medicago sativa seedlings. Funct Plant Biol 46(10):896-906. doi:10.1071/Fp19007

18. Ghasemzadeh A, Ashkani S, Baghdadi A, Pazoki A, Jaafar HZ, Rahmat A (2016) Improvement in Flavonoids and Phenolic Acids Production and Pharmaceutical Quality of Sweet Basil (Ocimum basilicum L.) by Ultraviolet-B Irradiation. Molecules 21 (9). doi:10.3390/molecules21091203

19. Gil M, Pontin M, Berli F, Bottini R, Piccoli P (2012) Metabolism of terpenes in the response of grape (Vitis vinifera L.) leaf tissues to UV-B radiation. Phytochemistry 77:89-98.

doi:10.1016/j.phytochem.2011.12.011

20. Henry-Kirk RA, Plunkett B, Hall M, McGhie T, Allan AC, Wargent JJ, Espley RV (2018) Solar UV light regulates flavonoid metabolism in apple (Malus x domestica). Plant Cell Environ 41(3):675-688. doi:10.1111/pce.13125

21. Ibanez S, Rosa M, Hilal M, Gonzalez JA, Prado FE (2008) Leaves of Citrus aurantifolia exhibit a different sensibility to solar UV-B radiation according to development stage in relation to photosynthetic pigments and UV-B absorbing compounds production. J Photochem Photobiol B 90(3):163-169. doi:10.1016/j.jphotobiol.2008.01.002

22. Inostroza-Blancheteau C, Reyes-Diaz M, Arellano A, Latsague M, Acevedo P, Loyola R, Arce-Johnson P, Alberdi M (2014) Effects of UV-B radiation on anatomical characteristics, phenolic compounds and gene expression of the phenylpropanoid pathway in highbush blueberry leaves. Plant Physiol Biochem 85:85-95. doi:10.1016/j.plaphy.2014.10.015

23. Jaiswal D, Pandey A, Mukherjee A, Agrawal M, Agrawal SB (2020) Alterations in growth, antioxidative defense and medicinally important compounds of Curcuma caesia Roxb. under elevated ultraviolet-B radiation. Environ Exp Bot 177:doi:ARTN 104152 10.1016/j.envexpbot.2020.104152

24. Kohler H, Contreras RA, Pizarro M, Cortes-Antiquera R, Zuniga GE (2017) Antioxidant Responses Induced by UVB Radiation in Deschampsia antarctica Desv. Front Plant Sci 8:921. doi:10.3389/fpls.2017.00921

25. Kusano M, Tohge T, Fukushima A, Kobayashi M, Hayashi N, Otsuki H, Kondou Y, Goto H, Kawashima M, Matsuda F, Niida R, Matsui M, Saito K, Fernie AR (2011) Metabolomics reveals comprehensive 
reprogramming involving two independent metabolic responses of Arabidopsis to UV-B light. Plant $\mathrm{J}$ 67(2):354-369. doi:10.1111/j.1365-313X.2011.04599.x

26. Li C, Chen M, Ji ML, Wang XX, Xiao W, Li L, Gao DS, Chen XD, Li DM (2020a) Transcriptome analysis of ripe peach (Prunus persica) fruit under low-dose UVB radiation. Sci Hortic-Amsterdam 259. doi:ARTN 108757 10.1016/j.scienta.2019.108757

27. Li X, Wang HB, Jin HL (2020b) Light Signaling-Dependent Regulation of PSII Biogenesis and Functional Maintenance. Plant Physiol 183(4):1855-1868. doi:10.1104/pp.20.00200

28. Liao XY, Liu W, Yang HQ, Jenkins GI (2020) A dynamic model of UVR8 photoreceptor signalling in UVB-acclimated Arabidopsis. New Phytol 227(3):857-866. doi:10.1111/nph.16581

29. Liu J, Liu Y, Wang Y, Abozeid A, Zu YG, Tang ZH (2017) The integration of GC-MS and LC-MS to assay the metabolomics profiling in Panax ginseng and Panax quinquefolius reveals a tissue- and species-specific connectivity of primary metabolites and ginsenosides accumulation. J Pharm Biomed Anal 135:176-185

30. Liu J, Liu Y, Wu K, Pan L, Tang ZH (2020a) Comparative analysis of metabolite profiles from Panax herbs in specific tissues and cultivation conditions reveals the strategy of accumulation. Journal of Pharmaceutical \& Biomedical Analysis:113368

31. Liu Y, Liu J, Abozeid A, Wu KX, Tang ZH (2020b) UV-B Radiation Largely Promoted the Transformation of Primary Metabolites to Phenols in Astragalus mongholicus Seedlings.

32. Liu Y, Liu J, Wang HZ, Wu KX, Tang ZH (2020c) Comparison of the global metabolic responses to UV$\mathrm{B}$ radiation between two medicinal Astragalus species: an integrated metabolomics strategy. Environmental \& Experimental Botany:104094

33. Liu Y, Liu J, Wang Y, Abozeid A, Tang ZH (2018a) The Different Resistance of Two Astragalus Plants to UV-B Stress is Tightly Associated with the Organ-specific Isoflavone Metabolism. Photochemistry \& Photobiology 94 (1)

34. Liu Y, Liu J, Wu KX, Guo XR, Tang ZH (2018b) A rapid method for sensitive profiling of bioactive triterpene and flavonoid from Astragalus mongholicus and Astragalus membranaceus by ultrapressure liquid chromatography with tandem mass spectrometry. Journal of Chromatography $B$ Analytical Technologies in the Biomedical Life Sciences 1085:110

35. M. Y. XU, K. X. WU, Liu Y, Liu J, Tang ZH (2020) Effects of light intensity on the growth, photosynthetic characteristics, and secondary metabolites of Eleutherococcus senticosus Harms. Photosynthetica 58:(7830546)

36. Ma J, Du G, Li X, Zhang C, Guo J (2015) A major locus controlling malondialdehyde content under water stress is associated with Fusarium crown rot resistance in wheat. Mol Genet Genomics 290(5):1955-1962. doi:10.1007/s00438-015-1053-3

37. Machado F, Dias MC, de Pinho PG, Araujo AM, Pinto D, Silva A, Correia C, Moutinho-Pereira J, Santos C (2017) Photosynthetic performance and volatile organic compounds profile in Eucalyptus globulus after UVB radiation. Environ Exp Bot 140:141-149. doi:10.1016/j.envexpbot.2017.05.008 
38. Nulton-Persson AC, Szweda LI, Sadek HA (2004) Inhibition of cardiac mitochondrial respiration by salicylic acid and acetylsalicylate. J Cardiovasc Pharm 44(5):591-595. 10.1097/00005344200411000-00012 doi:Doi

39. Ortega-Hernandez E, Nair V, Welti-Chanes J, Cisneros-Zevallos L, Jacobo-Velazquez DA (2019) Wounding and UVB Light Synergistically Induce the Biosynthesis of Phenolic Compounds and Ascorbic Acid in Red Prickly Pears (Opuntia ficus-indica cv. Rojo Vigor). Int J Mol Sci 20 (21). doi:10.3390/ijms20215327

40. Paajanen R, Julkunen-Tiitto R, Nybakken L, Petrelius M, Tegelberg R, Pusenius J, Rousi M, Kellomaki $S$ (2011) Dark-leaved willow (Salix myrsinifolia) is resistant to three-factor (elevated CO2, temperature and UV-B-radiation) climate change. New Phytol 190(1):161-168. doi:10.1111/j.14698137.2010.03583.x

41. Pieriste M, Neimane S, Solanki T, Nybakken L, Jones AG, Forey E, Chauvat M, Necajeva J, Robson TM (2020) Ultraviolet radiation accelerates photodegradation under controlled conditions but slows the decomposition of senescent leaves from forest stands in southern Finland. Plant Physiol Biochem 146:42-54. doi:10.1016/j.plaphy.2019.11.005

42. Rao MV, Paliyath G, Ormrod DP (1996) Ultraviolet-B- and ozone-induced biochemical changes in antioxidant enzymes of Arabidopsis thaliana. Plant Physiol 110(1):125-136. doi:10.1104/pp.110.1.125

43. Razack MA, Lee T (2013) Effects of Enhanced Ultraviolet-B (UV-B) Radiation and Antioxidative-type Plant Growth Regulators on Rice (Oryza sativa L.) Leaf Photosynthetic Rate, Photochemistry and Physiology. Journal of Agricultural Science (1916-9752) 5 (5):115-128

44. Ru WD, Pang YH, Gan YR, Liu Q, Bao JS (2019) Phenolic Compounds and Antioxidant Activities of Potato Cultivars with White, Yellow, Red and Purple Flesh. Antioxidants-Basel 8 (10). doi:ARTN 419 10.3390/antiox8100419

45. Santin M, Lucini L, Castagna A, Rocchetti G, Hauser MT, Ranieri A (2019) Comparative "phenolomics" and gene expression analyses in peach (Prunus persica) skin in response to different postharvest UV-B treatments. Plant Physiol Bioch 135:511-519. doi:10.1016/j.plaphy.2018.11.009

46. Shouhei M, Masato O (2018) Anxiolytic Effects of Acanthopanax senticosus HARMS Occur via Regulation of. In: Hirotaka, Oikawa, Hideo, Takekoshi, Masako, Hoshizaki. Autonomic Function and Activate Hippocampal BDNF?TrkB Signaling, Molecules

47. Takshak S, Agrawal SB (2019) Defense potential of secondary metabolites in medicinal plants under UV-B stress. J Photochem Photobiol B 193:51-88. doi:10.1016/j.jphotobiol.2019.02.002

48. Vidovic M, Morina F, Milic S, Zechmann B, Albert A, Winkler JB, Veljovic Jovanovic S (2015) Ultraviolet-B component of sunlight stimulates photosynthesis and flavonoid accumulation in variegated Plectranthus coleoides leaves depending on background light. Plant Cell Environ 38(5):968-979. doi:10.1111/pce.12471

49. Wang R, Shi L, Liu S, Liu Z, Liu Z (2019a) Mass spectrometry-based urinary metabolomics for the investigation on the mechanism of action of Eleutherococcus senticosus (Rupr. et. Maxim.) Maxim. 
leaves against ischemic stroke in rats. J Ethnopharmacol 241:111969-

50. Wang Y-H, Meng Y, Zhai C, Wang M, Avula B, Yuk J, Smith KM, Isaac G, Khan IA (2019b) The Chemical Characterization of Eleutherococcus senticosus and Ci-wu-jia Tea Using UHPLC-UVQTOF/MS. International Journal of Molecular Sciences 20 (3)

51. Wang Y, Liu S, Wang R, Shi L, Liu Z, Liu Z (2020) Study on the therapeutic material basis and effect of Acanthopanax senticosus (Rupr. et. Maxim.) Harms leaves in the treatment of ischemic stroke by PK-PD analysis based on online microdialysis-LC-MS/MS method. Food \& Function 11

52. Wu KX, Jia L, Yang L, Guo XR, Mu LQ, Hu XH, Tang ZH (2018) A Comparative Metabolomics Analysis Reveals the Tissue-Specific Phenolic Profiling in Two Acanthopanax Species. Molecules 23(8):2078

53. Xu MY, Wang YW, Wang QB, Guo SL, Liu Y, Liu J, Tang ZH, Wang ZY (2020) Targeted DevelopmentDependent Metabolomics Profiling of Bioactive Compounds in Acanthopanax senticosus by UPLCESI-MS. Nat Prod Commun 15 (4). doi:10.1177/1934578x20910553

54. Yan Y, Stoddard FL, Neugart S, Oravec M, Urban O, Sadras VO, Aphalo PJ (2020) The transgenerational effects of solar short-UV radiation differed in two accessions of Vicia faba L. from contrasting UV environments. J Plant Physiol 248. doi:ARTN 153145 10.1016/j.jplph.2020.153145

55. Yang SH, Wang LJ, Li SH, Duan W, Loescher W, Liang ZC (2007) The effects of UV-B radiation on photosynthesis in relation to Photosystem II photochemistry, thermal dissipation and antioxidant defenses in winter wheat (Triticum aestivum L.) seedlings at different growth temperatures. Funct Plant Biol 34(10):907-917. doi:10.1071/Fp07083

56. Zeiger E, Field C (1982) Photocontrol of the Functional Coupling between Photosynthesis and Stomatal Conductance in the Intact Leaf: Blue Light and Par-Dependent Photosystems in Guard Cells. Plant Physiol 70(2):370-375. doi:10.1104/pp.70.2.370

57. Zhang H, Wang S, Jin LH (2020) Acanthopanax senticosus polysaccharide regulates the intestinal homeostasis disruption induced by toxic chemicals in Drosophila. Phytotherapy Research 34 (1)

\section{Tables}

Due to technical limitations, table 1 is only available as a download in the Supplemental Files section.

\section{Figures}




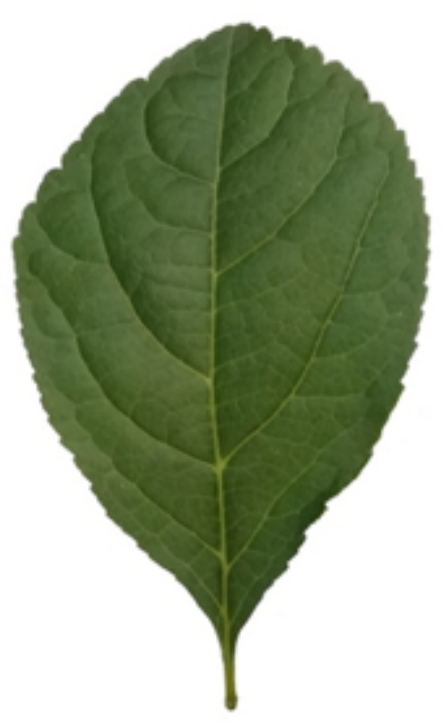

(A)

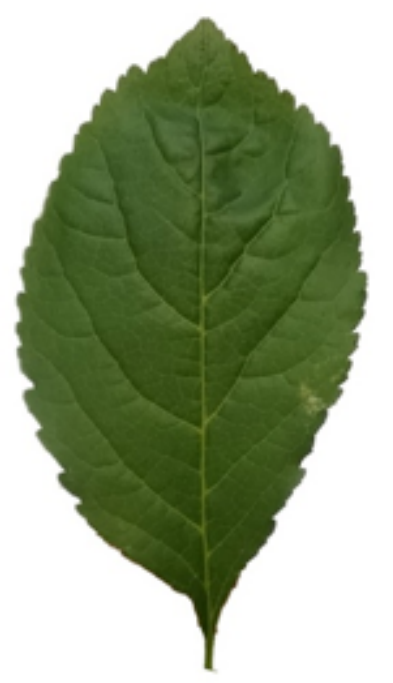

(B)

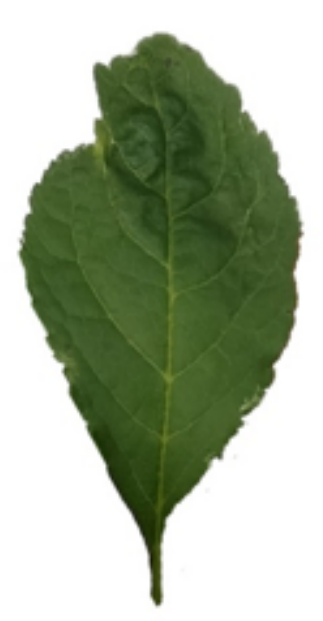

(C)

Figure 1

UV-B-treated photos of A. senticosus. (A) CK; (B) MU; (C) HU

Photo

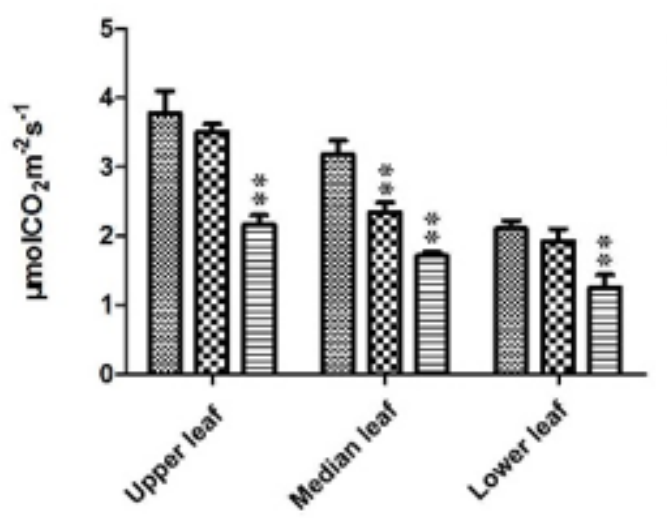

Ci

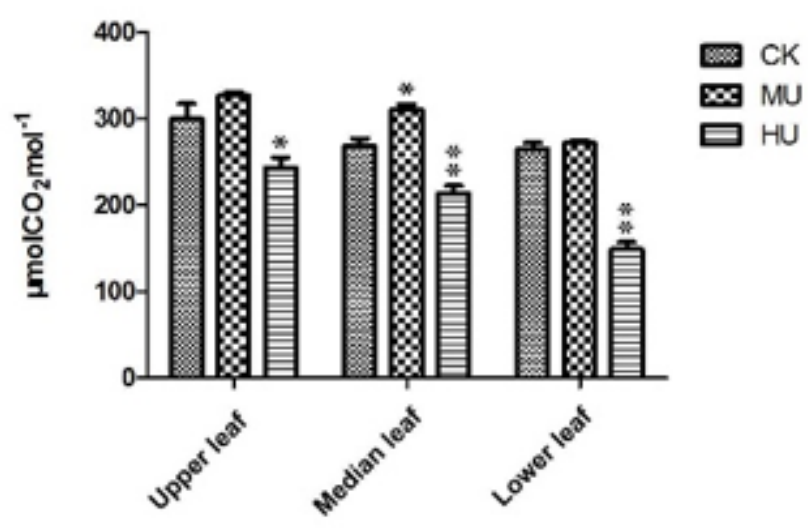

Cond

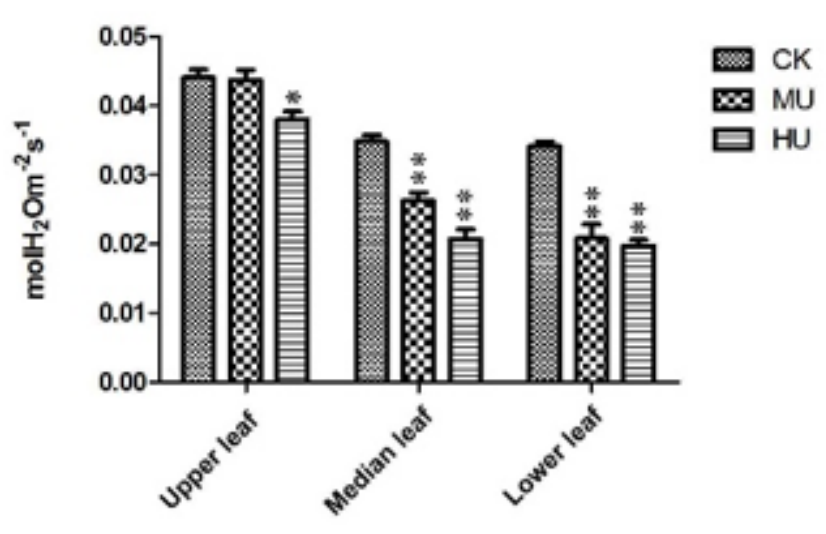

Trmmol

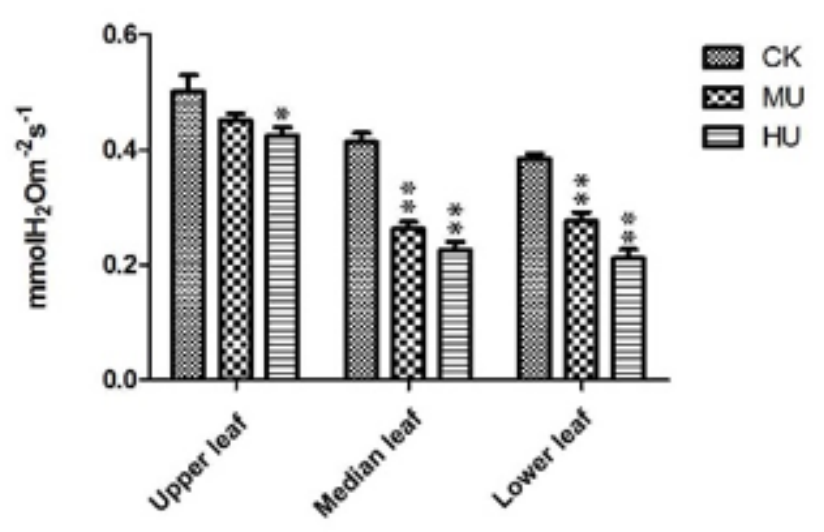

Figure 2 
Effect of different UV-B treatment on gas exchange parameters in different leaf positions of A. senticosus * indicates significant differences in the same tissue sites.
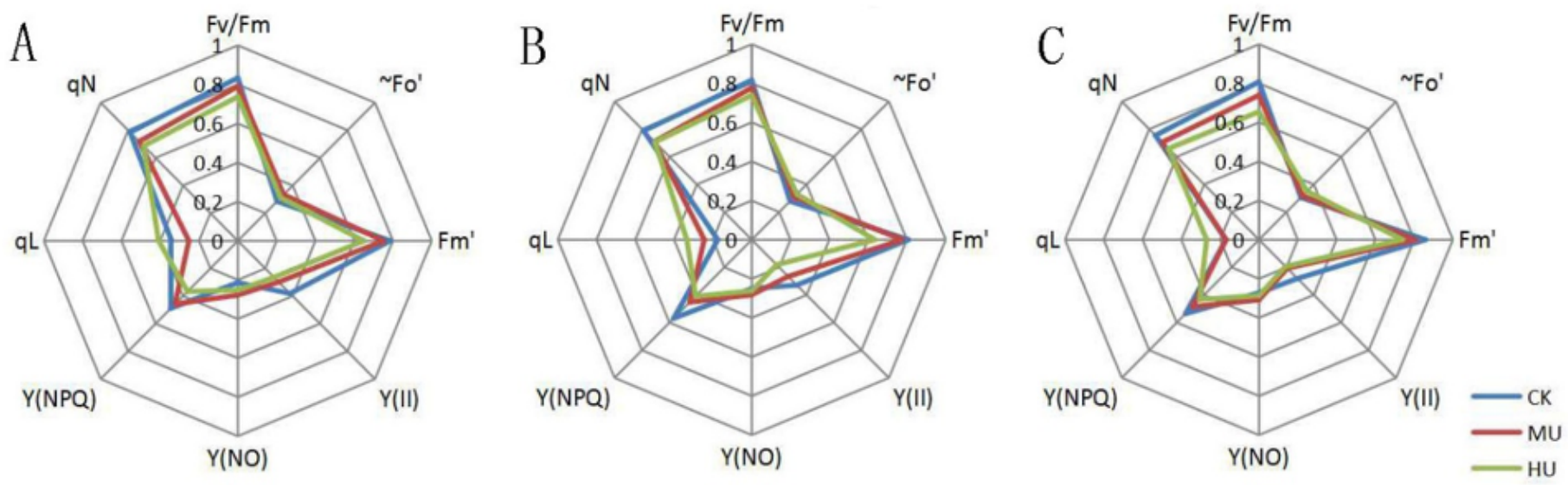

\section{Figure 3}

Effect of UV-B treatment on chlorophyll fluorescence at different leaf positions of A. senticosus. (A) Upper Leaf; (B) Median Leaf; (C) Lower Leaf

MDA

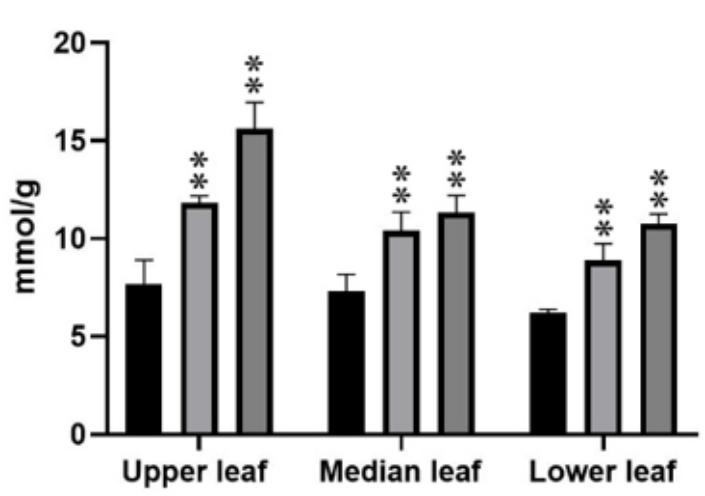

Proline

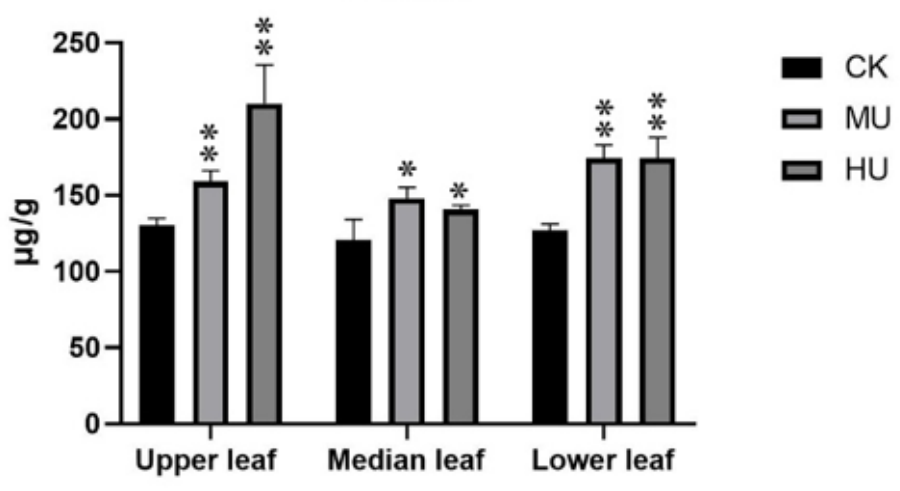

\section{Figure 4}

Effect of UV-B treatment on MDA and Proline content in different leaf positions of A. senticosus. 


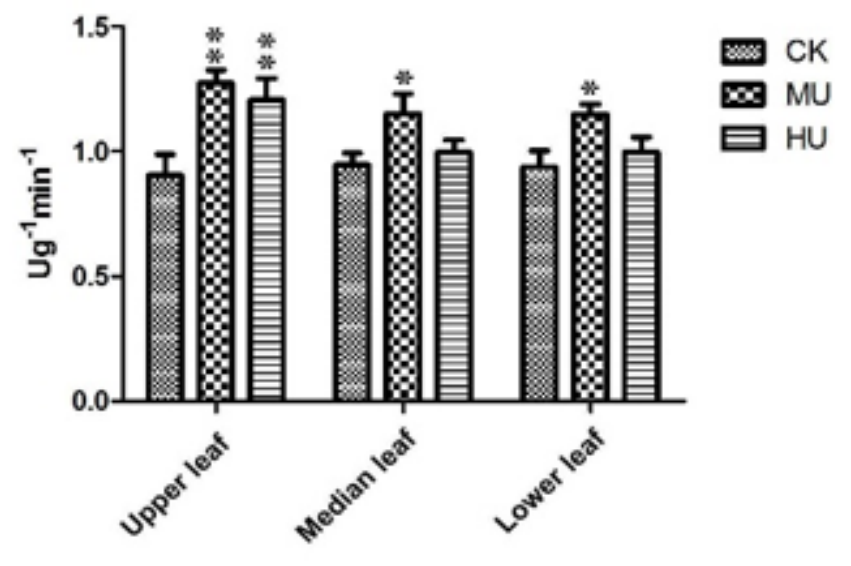

POD activity

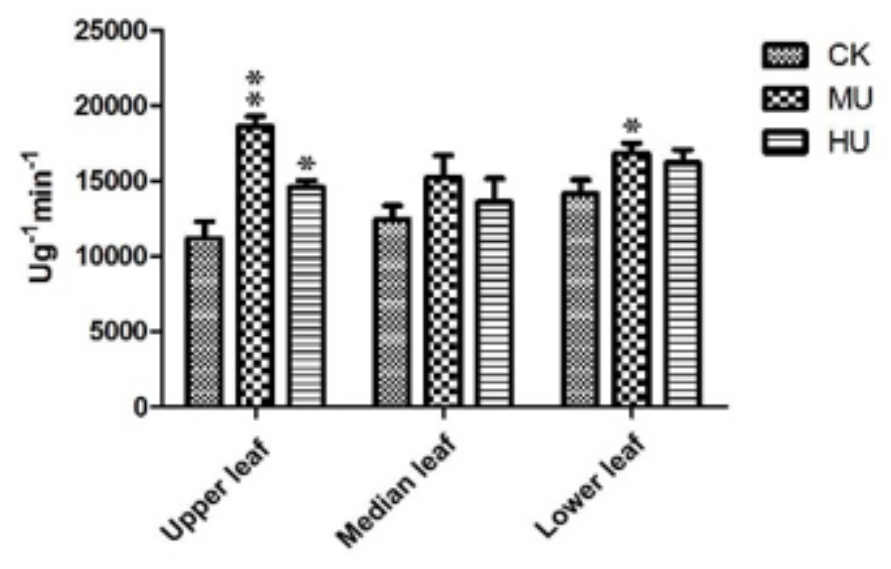

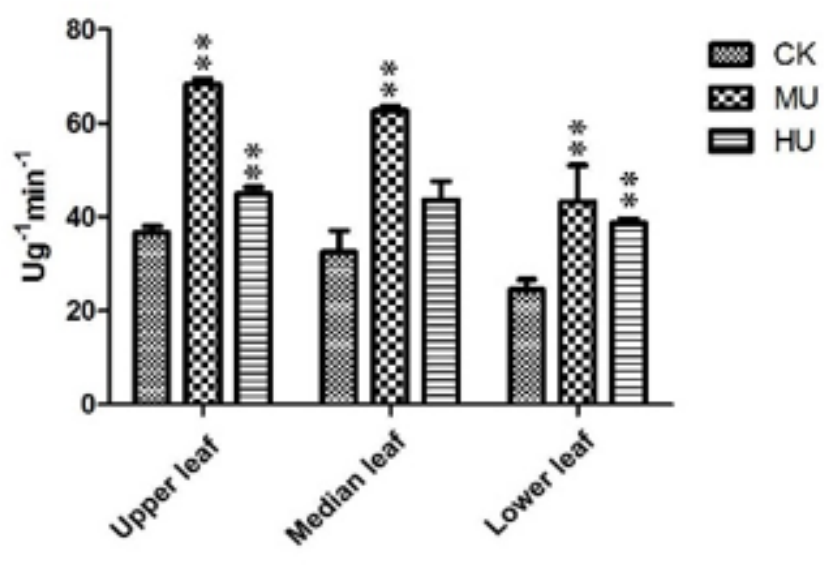

SOD activity

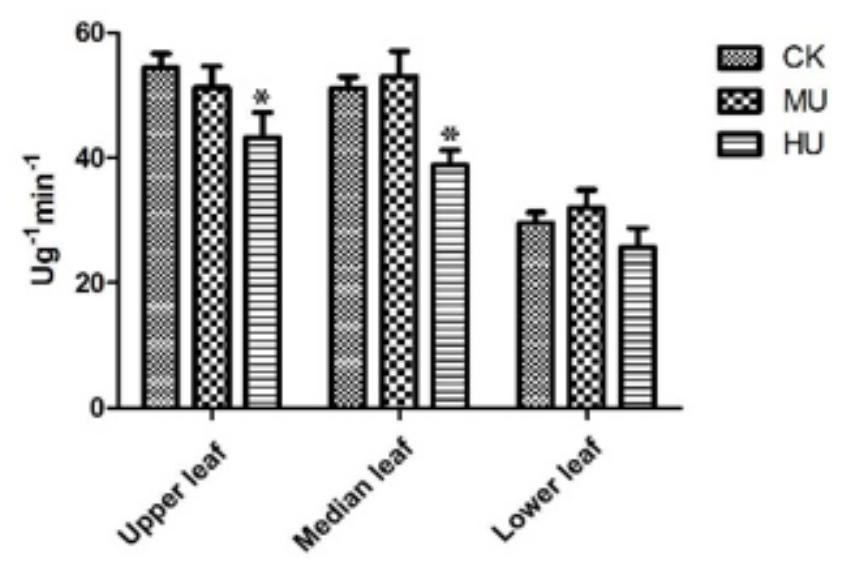

Figure 5

Effect of UV-B treatment on antioxidant enzyme activity in different leaf positions of A. senticosus. 
Eleutheroside B

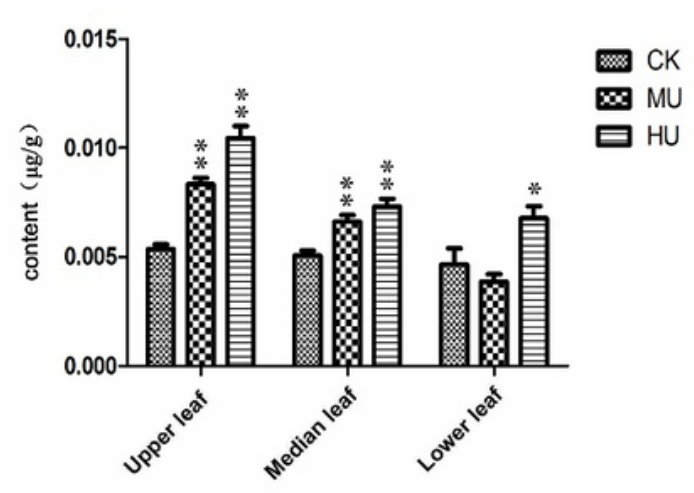

Isofraxidin

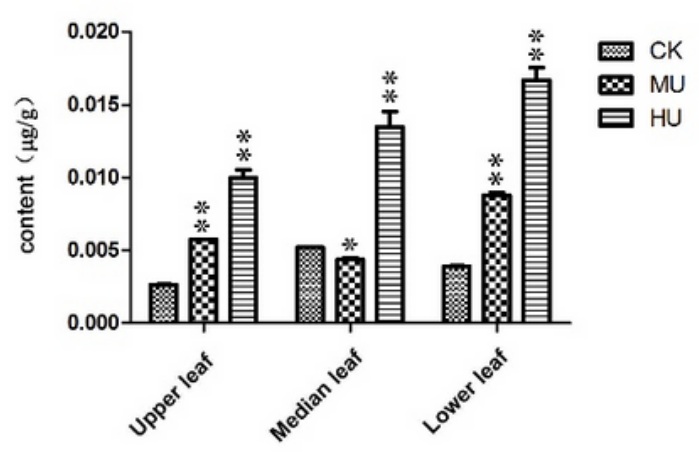

0leanolic acid

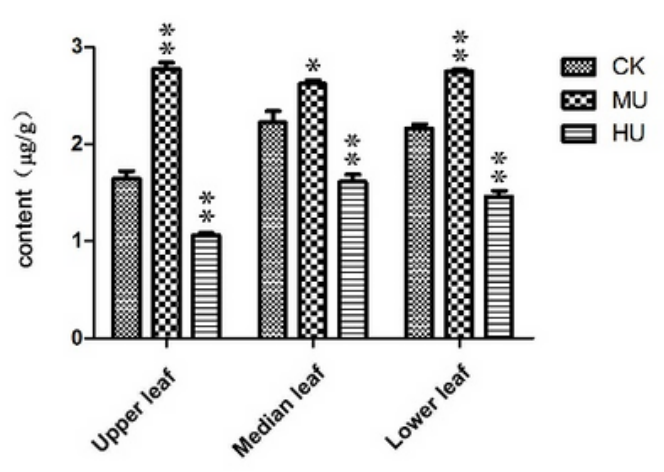

Eleutheroside E

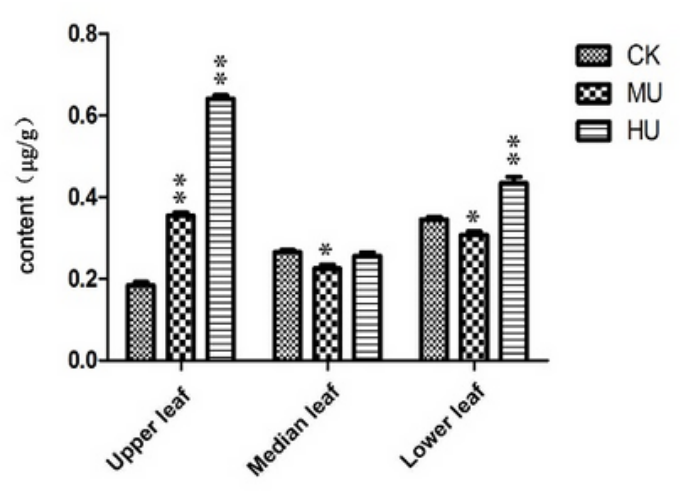

Hyperoside

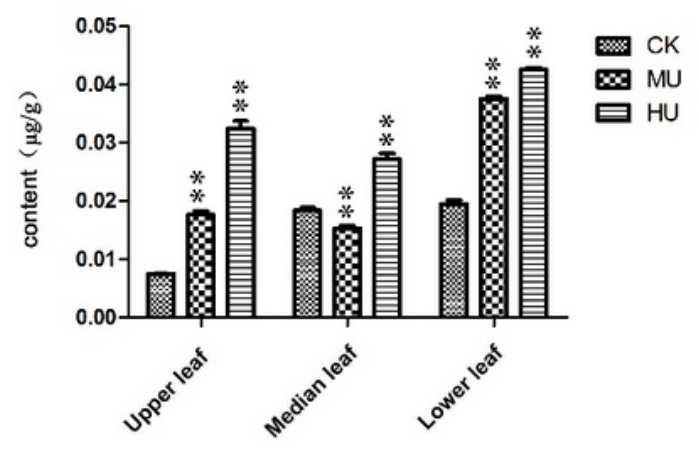

Q Value

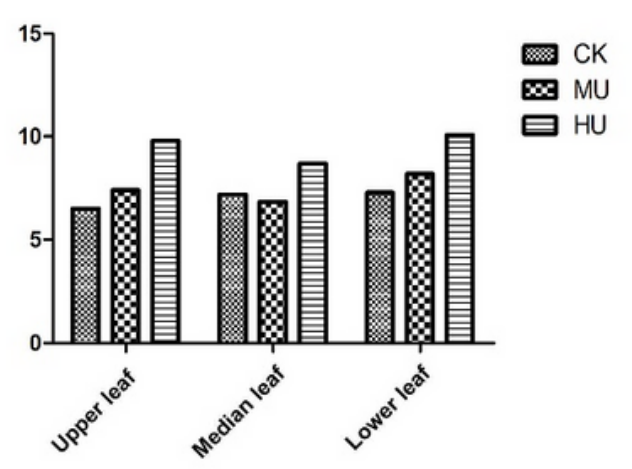

Figure 6

The content of five major bioactive compounds in different leaf positions of A. senticosus and comprehensive Q value. * indicates significant differences in the same tissue sites of different species. 


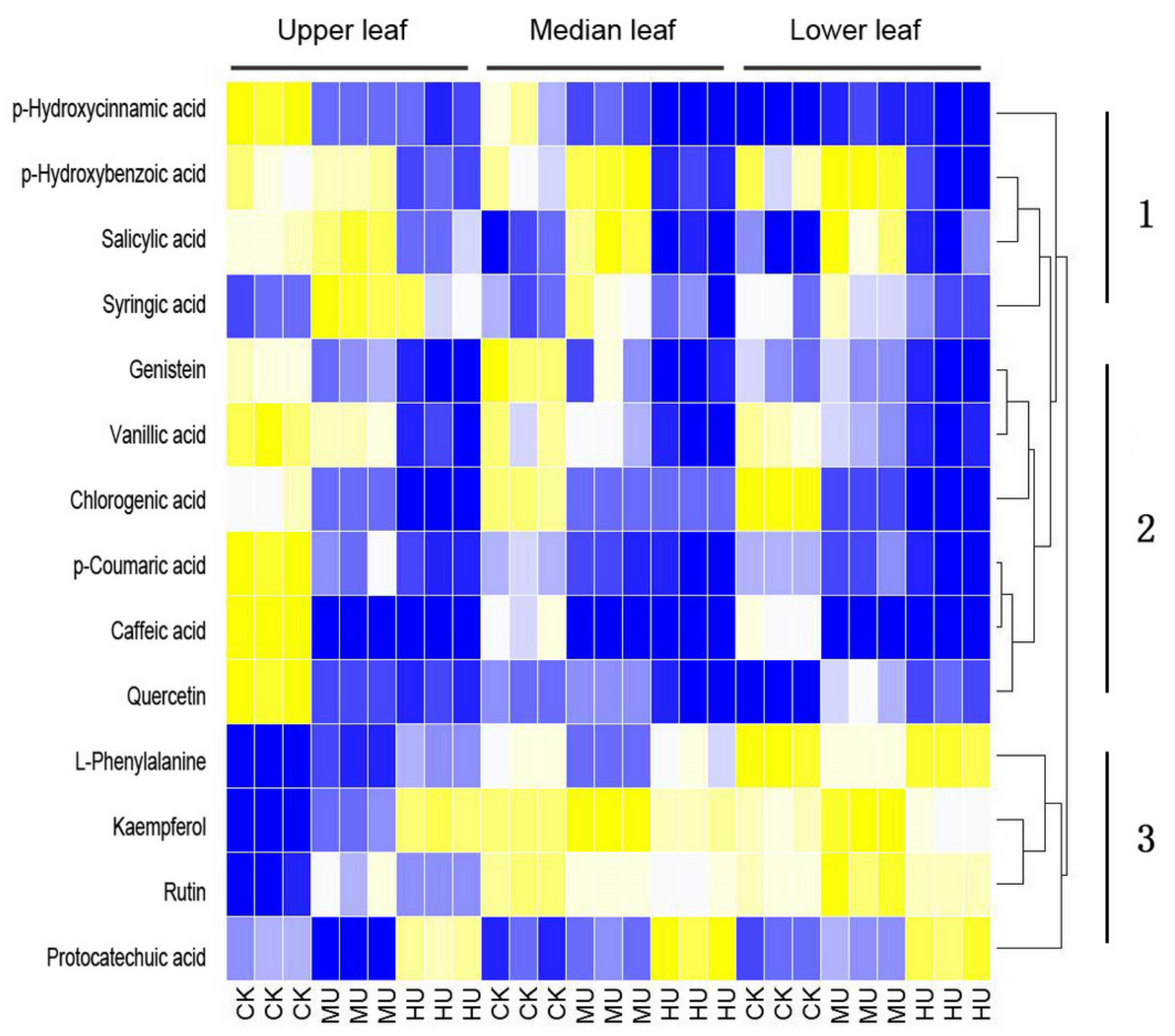

$\begin{array}{lllllllllllllll}0.00 & 0.07 & 0.13 & 0.20 & 0.27 & 0.33 & 0.40 & 0.47 & 0.53 & 0.60 & 0.67 & 0.73 & 0.80 & 0.87 & 0.93\end{array}$

\section{Figure 7}

Effect of UV-B radiation on the distribution of phenolic compounds in leaves of A. senticosus. Three biological replicates per group, blue indicates low compound accumulation; yellow indicates high compound accumulation. 


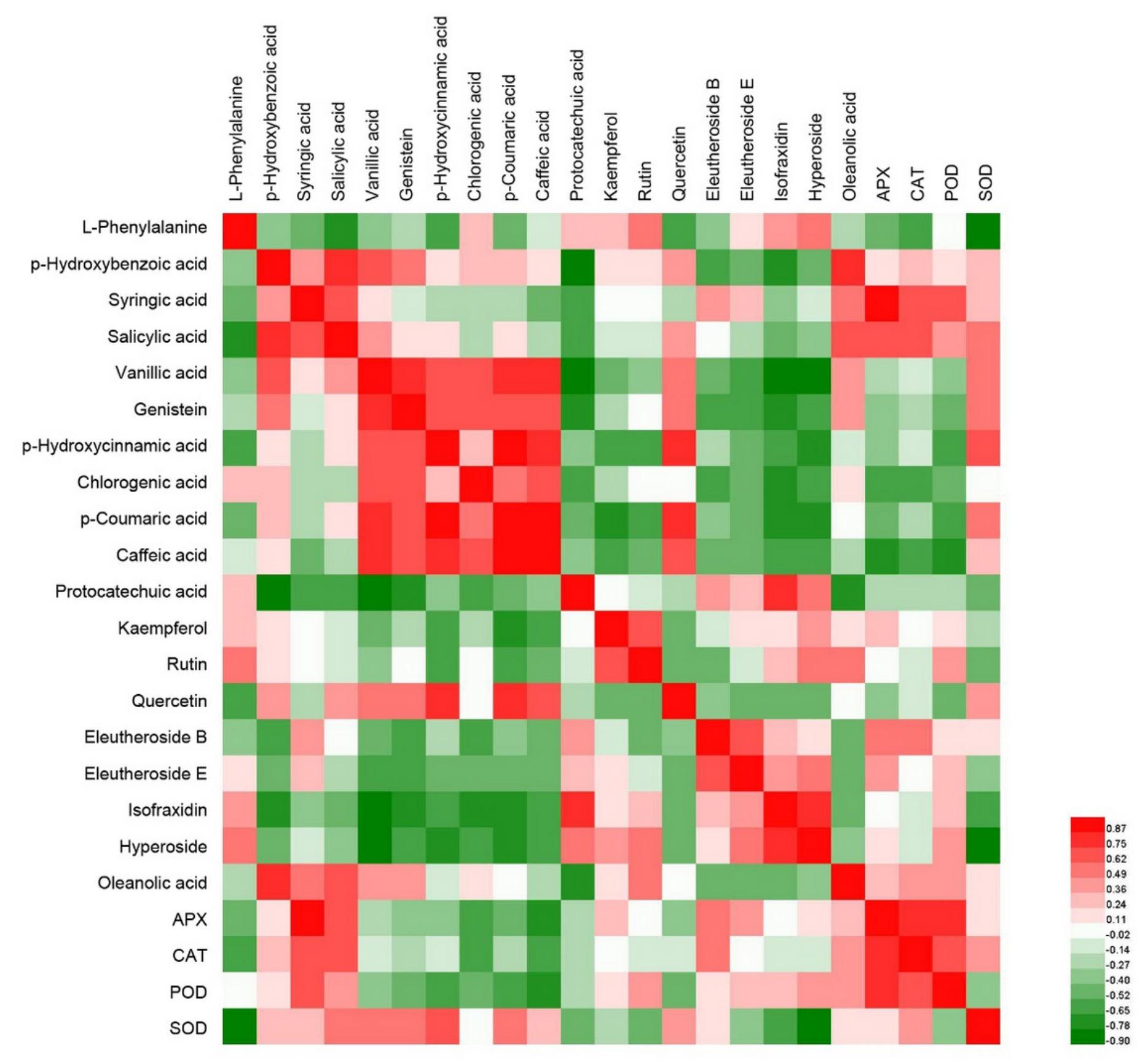

\section{Figure 8}

Correlation analysis of A. senticosus antioxidant enzymes, pharmaceutically active ingredients and phenolic compounds after UV-B treatment. Green represents negative correlation; red represents positive correlation.

\section{Supplementary Files}

This is a list of supplementary files associated with this preprint. Click to download.

- Supplementarymaterials.docx 
- Table.xlsx

Page 23/23 